\title{
Genetic Parameters and Development of a Selection Index for Breeding Red Raspberries for Processing
}

\author{
M. Joseph Stephens ${ }^{1}$, Peter A. Alspach, and Ron A. Beatson \\ The New Zealand Institute for Plant \& Food Research Limited, Motueka Research Centre, 55 Old Mill \\ Road, Motueka 7198, New Zealand \\ Chris Winefield \\ Lincoln University, Faculty of Agriculture and Life Sciences, P.O. Box 84, Lincoln 7647, Canterbury, \\ New Zealand \\ Emily J. Buck \\ The New Zealand Institute for Plant \& Food Research Limited, Batchelar Road, Private Bag 11600 , \\ Palmerston North 4442, New Zealand
}

\begin{abstract}
AdDITIONAL INDEX wORDs. Rubus idaeus, yield, fruit firmness, heritability, genetic correlation
Abstract. New commercial red raspberry (Rubus idaeus) cultivars suited to machine-harvesting and processing markets need to be high-yielding and have good fruit quality attributes, including fruit firmness, sugar content, acidity, flavor, and health properties. Combining many traits in one genotype is a challenge for breeders, especially for traits negatively correlated with yield. Despite its potential, the use of multiple-trait selection through selection indices has had limited application in fruit breeding. In this study, we estimated variance components, heritabilities, phenotypic and genetic correlations and breeding values for total yield (TYLD), harvest span, mid-harvest day and fruit quality traits, firmness (FIRM), soluble solids (SS), acidity (ACID), total anthocyanins (TACY), and total ellagitannins (TELG) from 1008 seedling genotypes based on 85 families derived from 45 parents harvested over three seasons in Washington state. Narrow-sense heritability estimates ranged from moderately low (0.22 for TYLD) to moderately high ( 0.73 for SS). All traits measured had positive genetic correlations with TYLD except for ACID $(-0.35)$ and TACY $(-0.28)$. Genotype $\times$ year $(G \times Y)$ interaction was high for TYLD and low for fruit quality attributes FIRM, SS, ACID, TACY, and TELG, and interactions were higher between the first (2009) and second (2010) seasons than between the second (2010) and third (2011) seasons. Using economic weights and breeding values derived from multivariate analysis for TYLD, FIRM, SS, and TACY, we constructed a selection index designed to assist with multiple-trait selection for population improvement and the development of commercial raspberry cultivars.
\end{abstract}

The New Zealand Institute for Plant \& Food Research Limited and Northwest Plant Company have developed a raspberry breeding program based in Whatcom County, WA, that is focused on developing new machine-harvested cultivars suited to processing markets. Key targets of the program include: high yield, firm fruit that can be harvested by machine, high soluble solids, moderately high acidity, excellent flavor, improved human health attributes, and plant disease resistance.

Breeding for high yield presents its own set of challenges for the breeder and for raspberry, this has been investigated in New Zealand by Stephens et al. (2009) and in the United States by Stephens et al. (2012). In Washington state, Stephens et al. (2012) identified berry weight and lateral length as key components of yield that, when measured in the first 2 fruiting years from planting, had some predictive ability on total yield in later years, thus enabling a breeder to concentrate on the most promising genotypes when harvesting. As well as high yield, successful cultivars also need favorable fruit quality attributes including firm fruit, high soluble solids, good acidity, and, more recently, those compounds that are associated with improved

Received for publication 1 May 2012. Accepted for publication 7 June 2012. We thank Julie Enfield, Micah Blondeau, Lawrence Graham, and Donna Graham who helped to coordinate the harvest; David Stevenson and Dave Andersen for chemistry analyses; and Adam Enfield and Enfield Farms Inc. for field management.

${ }^{1}$ Corresponding author. E-mail: jo.stephens@plantandfood.co.nz. human health benefits. Although several sources of firmness in raspberry have been identified (Knight et al., 1989), including $R$. occidentalis, little has been published on the inheritance of fruit firmness, soluble solids, and acidity in red raspberries (Barritt, 1982). A group of polyphenols, called hydrolysable tannins, that have relatively newly discovered human health benefits (Cerda et al., 2005; Ross et al., 2007; Seeram et al., 2007; Viljanen et al., 2004), include ellagitannins, which are also present in red raspberries (Bakkalbasi et al., 2009; Bushman et al., 2004; Khanizadeh et al., 2009). We found no published information on the genetic inheritance of these compounds in red raspberry.

Anthocyanins, also polyphenols and belonging to the flavonoid group, are powerful antioxidants found in relatively high concentrations in raspberries (Barritt and Torre, 1975) and may contribute to high health properties of raspberry (Olsson et al., 2004). These compounds are genetically inherited and have high heritability in raspberry (Connor et al., 2005; Dossett et al., 2008; Stephens et al., 2009); therefore, potential exists to breed fruit with increased anthocyanin content. However, anthocyanins have been shown to be negatively correlated with total yield in red raspberry (Stephens et al., 2009) and thus progress developing high-yielding high anthocyanin types might be more difficult.

Developing cultivars with high yield as well as improved fruit quality is a challenge for raspberry breeders, because a number of desirable commercial traits are needed to be 
combined into one plant. The use of a selection index approach as described by Falconer and Mackay (1996) for such multipletrait selection could offer a solution. This approach, designed to give the most rapid improvement of economic value, uses an appropriate weight given to each trait according to its economic importance, its heritability, and the genetic and phenotypic correlations between the different traits (Falconer and Mackay, 1996). However, despite its potential, we found only a few examples of this approach in fruit breeding (Beatson et al., 2011; de Oliveira et al., 2008).

In this article, we combine the yield information reported in our first article (Stephens et al., 2012) with fruit quality measurements (i.e., fruit firmness, soluble solids, acidity, total anthocyanins and ellagitannins) to develop and demonstrate the use of a selection index for breeding new raspberry cultivars for processing markets. In addition, we set out to study the influence of the first, second, and third years on fruit quality traits to understand genotype $\times$ year $(\mathrm{G} \times \mathrm{Y})$ interaction.

\section{Materials and Methods}

Plants and Experimental Design. Details of the parental material and experimental design are described by Stephens et al. (2012). Briefly, controlled crosses were carried out in a double pairwise design involving 45 parents, which should have resulted in 90 full-sib families with each parent being used in four crosses (twice as a female and twice as a male). However, failure of some crosses and poor seed germination resulted in 85 families and a few instances in which the reciprocal cross was used because of timing of the availability of flowers and pollen. Parents were all floricane-fruiting red raspberry types and consisted of 18 breeding selections and three cultivars from the Plant and Food Research or Plant and Food Research-Northwest Plant raspberry breeding program and 24 named cultivars from North American and Canadian breeding programs. Recent papers (Piepho and Williams, 2006) indicated that an $\alpha$-design (Patterson and Williams, 1976) was appropriate. There were two complete blocks, each with 12 subblocks of seven plots (i.e., 84 plots per block, which was sufficient because two of the 85 families had enough plants for only one plot). Each plot consisted of six full-sib seedling plants. Planted in May 2008, the trial was located at Enfield Farms Inc., Lynden, WA (lat. $48.935^{\circ} \mathrm{N}$, long. $\left.122.542^{\circ} \mathrm{W}\right)$. The seedlings were planted in rows with spacing $3 \mathrm{~m}$ between rows and $1 \mathrm{~m}$ between seedlings and managed according to standard agronomic practice. Thus, there was a total of 1008 plants in the trial with 12 plants per family and two instances in which there were six plants per family.

Yield and fruit quality data were collected in each of the 2009, 2010, and 2011 seasons when the plants were 1, 2, and 3 years old (from planting in the field). From the first plant per plot in 2009 ( $\mathrm{n}=168$ plants) and the first and second plants in each plot in 2010 and 2011 ( $n=336$ plants), TYLD (grams) was measured by hand-picking and weighing total weight of ripe fruit every $5 \mathrm{~d}$ throughout the season. For each harvested plant, a loess smooth curve of cumulative yield on date was interpolated to derive the midharvest date [MHD (date at which 50\% of the final yield had been harvested)] and harvest span [HSP (number of days over which the middle $80 \%$ of the crop was picked)].

For each season, for fruit firmness and chemistry, three times during the season (early, middle, and late) 30 berries were picked from each plant, placed into a clamshell container, and taken to the laboratory where fruit firmness was tested with a firmness tester (Firmtech 2; Bioworks, Wamego, KS) after which the samples frozen $\left(-20^{\circ} \mathrm{C}\right)$ for later chemical analysis. The firmness tester was set to measure the peak force during a 2-mm compression from the outside of each of 25 random fruit, which were placed collar down. The mean of these values overall harvests (i.e., 75 fruit total) was taken as the measure of firmness (Newtons) for the plant. Thawed fruit from the three harvests were combined and crushed in a potato ricer to extract juice and SS (percent) recorded using a digital pocket refractometer (PAL-1; Atago, Tokyo, Japan) and ACID (milligrams per gram) measured by titrating $2 \mathrm{~mL}$ of berry juice in $40 \mathrm{~mL}$ of water with $0.1 \mathrm{M} \mathrm{NaOH}$ to $\mathrm{pH} 8.2$ on an autotitrater (T70; Mettler Toledo, Zurich, Switzerland). For determination of TACY (milligrams per $100 \mathrm{~mL}$ ) and TELG (milligrams per $100 \mathrm{~mL}$ ), analyses were carried out on a 20-series analytical high-performance liquid chromatograph (Shimadzu, Portland, OR) with a column oven, autosampler, vacuum solvent degas module, and diode-array detector. The column used was a $150 \times 2-\mathrm{mm}$, Synergi Polar-RP, 4- $\mu \mathrm{m}$ particle size, $80 \AA$ pore size, fitted with a Security-Guard $3 \times$ 2-mm Polar RP guard cartridge (Phenomenex, Auckland, New Zealand). Flow rate was $0.6 \mathrm{~mL} \cdot \mathrm{min}^{-1}$ and column oven temperature $50{ }^{\circ} \mathrm{C}$. Solvents were (A) methanol and (B) $2 \%$ aqueous formic acid, and the initial mobile phase was $5 \% \mathrm{~A}$ and $95 \% \mathrm{~B}$. The time program of pump B concentration was set up as $92 \%$ at $2.5 \mathrm{~min}, 82 \%$ at $5 \mathrm{~min}, 72 \%$ at $7 \mathrm{~min}, 58 \%$ at 9.5 $\mathrm{min}, 45 \%$ at $11 \mathrm{~min}, 30 \%$ at $12 \mathrm{~min}, 20 \%$ from 12.5 to $13.3 \mathrm{~min}$, returning to $95 \%$ at $13.8 \mathrm{~min}$, and staying at that concentration until the end of the run at $15 \mathrm{~min}$. Sample injections were $10 \mu \mathrm{L}$ of centrifuged juice, diluted if necessary with aqueous $1 \%$ formic acid.

Quantification of anthocyanins was carried out at $520 \mathrm{~nm}$, in comparison with standard solutions of cyanidin glucoside. Results were expressed as milligrams cyanidin glucoside equivalent per $100 \mathrm{~g}$ fruit or $100 \mathrm{~mL}$ of juice. Quantification of ellagitannins was carried out at $295 \mathrm{~nm}$ with standard solutions of Sanguiin H6.

Statistical APPROACH. We calculated variance components, best linear unbiased predictors (BLUP), and empirical breeding values (eBV) (Henderson, 1977) for each trait using the mixed model approach (Lynch and Walsh, 1998) described by Stephens et al. (2012). Briefly, there were no fixed effects in the models and random effects included genotypes (i.e., individual plants), block, and subblock. Potential spatial effects and $\mathrm{G} \times \mathrm{Y}$ interactions for each trait were investigated as described by Stephens et al. (2012) with spatial effects investigated by fitting a first-order autocorrelation structure to both rows and plant position within row (Gilmour et al., 1997) and $\mathrm{G} \times \mathrm{Y}$ interactions analyzed by fitting all pairwise bivariate models in which the set of observations for a trait in a season (i.e., 2009:2010, 2010:2011, 2009:2011) was taken to be a separate trait. $\mathrm{G} \times \mathrm{Y}$ correlations $\left(\mathrm{r}_{\mathrm{G} \times \mathrm{Y}}\right)$ were estimated from the variance components and their SES were obtained using bootstrap with 1000 iterations. Genetic and phenotypic correlations were estimated from the additive genetic variancecovariance matrix of the bivariate analysis. The phenotypic correlation is between observed raw values (adjusted by the model for experimental design) and includes environmental variance, whereas the genetic correlation includes only additive genetic variance, excludes environmental variance, and can also be derived from correlation of eBV. 
BLUP breeding values were obtained for the seedlings from the univariate analysis. Because the pedigree information was included, it was also possible to estimate the eBV for each parent. Narrow-sense heritability estimates $\left(h^{2}\right)$ were calculated from the bivariate analysis as the ratio between the additive genetic variance and the sum of the residual variance and the additive genetic variance averaged overall estimates for that trait. SES for heritability were estimated using the Taylor series expansion (Dieters et al., 1995).

We fitted a multivariate model with four traits (TYLD, FIRM, SS, TACY) using mean data from all three seasons (2009, 2010, 2011) and calculated breeding values for the parents and all genotypes. BLUP breeding values could then be applied to the breeders' economic weights for construction of the selection index (Falconer and Mackay, 1996) for multiple-trait selection. This differs from the Smith-Hazel selection index method, in which the b-values (weighting factors) are calculated from phenotypic values and genetic covariances (Hazel et al., 1994). In our study the genetic covariances among traits were taken into account in the calculation of the eBVs and so the selection index for each seedling was simply the sum of the products of the economic weights for each trait and the eBVs. One of the difficulties with applying an index is the lack of a procedure to weight the characters of economic importance and assigning breeders' weights to these. We assigned economic weights derived from the net increase in profit of the production for a unit change in one trait as defined by Hazel (1943). Thus, our weights were $0.2,80,1500$, and 0.8 for TYLD, SS, FIRM, and TACY, respectively. It should be noted that the economic weights for TYLD and FIRM are likely to be the most accurate, because they are based on fruit value; however, weights for SS and TACY are somewhat arbitrary. To demonstrate the effect of altering the economic weights, we also calculated the index based on 10 for TACY.

All statistical analyses were conducting using R 2.12.0 (R Core Development Team, 2010) and the mixed models were fitted using the asreml-r package (Butler et al., 2006).

\section{Results}

Spatial effects were very small, as determined by the magnitude of the estimated correlations relative to their SES, the semivariograms, and the likelihood ratio test (data not shown); therefore, they were not included in the final models. The residual plots indicated that the assumption of normality was tenable for all traits (data not shown).

We estimated breeding values for parents of our population for the traits we measured (Table 1) and these indicate the best breeding parents for each trait. Selections ZNK018 and ZNK019, which are full-sibs, had the highest values for total yield, although 23 of the 45 parents were within one least significant difference (LSD5\% level) of the top parent. The best parent for late harvest season was ZN05022, which was also best for long harvest season. For early harvest season, ZN05005 was the best parent and 'Prelude', another good early harvest parent, was best for short season. Selection ZNK019 was an outstanding parent for improving FIRM, being $0.06 \mathrm{~N}$ [greater than one LSD (5\% level)] firmer than the second ranked parent ('Coho'). 'Cuthbert' was the highest ranked parent for SS. ZN05005 was the best parent for high TACY and 'Wakefield' was outstanding for both increased ACID and increased TELG (Table 1).
'Wakefield' was the only parent within one LSD of the top for all traits (excluding MHD and HSP), except for SS and FIRM, for which it was ranked third. For MHD, FIRM, TACY, and TELG, the maximum parental eBVs were several times their minima, and considerable variation among parents existed in other traits (Table 1). It is noted that there were 22 breeding line selections among the 45 parents and they made up nine of the top 10 and only two of the bottom 10 parents for TYLD. Breeding lines also made up seven of the top 10 and only one of the bottom 10 parents for FIRM.

Heritability estimates varied from low $\left(h^{2}=0.18\right)$ for TYLD in 2010 to high $\left(h^{2}=0.81\right)$ for SS in 2011 (Table 2) and were consistent overall years. All fruit chemistry traits had higher heritability estimates than TYLD with the highest mean heritability for SS $\left(h^{2}=0.73\right)$ followed by TACY $\left(h^{2}=0.67\right)$, MHD $\left(h^{2}=0.59\right)$, FIRM $\left(h^{2}=0.54\right)$, TELG $\left(h^{2}=0.46\right)$, ACID $\left(h^{2}=0.45\right)$, HSP $\left(h^{2}=0.42\right)$, and TYLD $\left(h^{2}=0.22\right)$. No meaningful heritability estimates were obtained for HSP and MHD for 2009.

Genetic and phenotypic correlations (Table 3) ranged from negligible to highly negative or positive. In general, over the eight traits, the two types of correlations were of a similar magnitude across the 3 years of the trial ( $r=0.82$ in 2009, $r=0.89$ in 2010, $r=0.88$ in 2011, respectively) but for any one trait, the genetic correlation was of greater magnitude than the phenotypic one. A positive genetic correlation was found between TYLD and both MHD and HSP (Table 3). For FIRM, high genetic $\left(r_{G}=0.51\right)$ but low phenotypic $\left(r_{P}=0.06\right)$ correlation was found with TYLD. SS $\left(r_{G}=0.27\right)$ and TELG $\left(r_{G}=0.18\right)$ were positively correlated with TYLD, whereas ACID $\left(r_{G}=-0.35\right)$ and TACY $\left(r_{G}=-0.28\right)$ were negatively correlated with TYLD. Phenotypic correlations between TYLD and each of these four traits were weak (Table 3). We found a strong genetic correlation $\left(r_{G}=0.8\right)$ and moderately strong phenotypic correlation $\left(r_{P}=0.54\right)$ between MHD and HSP. Moderately strong negative genetic and phenotypic correlations were found between TACY and MHD, HSP, SS, and, in fact, most of the negative correlations we found were associated with TACY (Table 3).

We found low $\mathrm{G} \times \mathrm{Y}$ interaction for FIRM, SS, ACID, TACY, and TELG and a higher G $\times$ Y interaction for TYLD, MHD, and HSP (Table 4). No meaningful G $\times$ Y correlations involving 2009 data were extracted from variance components from our model for TYLD or MHD.

We applied economic weights to breeding values, which were obtained from multivariate analysis for TYLD, FIRM, $\mathrm{SS}$, and TACY to derive the selection index. These weights can be adjusted to put more or less emphasis on a trait and we have presented two scenarios (Fig. 1), which show breeding values and raw data for all genotypes. Comparison of the raw data distribution with that of the eBV clearly shows the greater "shrinkage" for traits with lower heritability (e.g., TYLD). The graphical representation is particularly useful in deciding appropriate weights for traits for which the economic value is difficult to determine. For example, index selection with emphasis placed on TYLD and FIRM could result in a mean decrease in TACY in the selected progeny (Fig. 1), whereas more emphasis on TACY could lead to selecting progeny with lower TYLD (Fig. 1). To gain the "best of both worlds," an economic value for TACY somewhere in the middle of our estimates might be used, which would result in gains for both TYLD and TACY at a slower rate than if we selected based on TYLD or TACY itself. 
Table 1. Mean overall years of the parental empirical breeding values for total yield and fruit quality parameters sorted from highest to lowest yield for parents of red raspberry pairwise study (sorted from highest to lowest yield). ${ }^{z}$

\begin{tabular}{|c|c|c|c|c|c|c|c|c|}
\hline \multirow[b]{2}{*}{ Parent } & \multicolumn{8}{|c|}{ Yield and fruit quality parameters ${ }^{y}$} \\
\hline & TYLD (g/plant) & MHD & $\operatorname{HSP}(\mathrm{d})$ & FIRM $(\mathrm{N})$ & SS (\%) & $\mathrm{ACID}\left(\mathrm{mg} \cdot \mathrm{g}^{-1}\right)$ & TACY $(\mathrm{mg} / 100 \mathrm{~mL})$ & TELG $(\mathrm{mg} / 100 \mathrm{~mL})$ \\
\hline ZNK019 & 3974 & 23 July & 25.4 & 0.52 & 9.5 & 19.1 & 53.8 & 39.4 \\
\hline ZNK018 & 3934 & 19 July & 25.7 & 0.40 & 9.0 & 16.7 & 59.8 & 44.2 \\
\hline ZNK063 & 3871 & 21 July & 25.6 & 0.34 & 9.4 & 17.9 & 57.3 & 34.2 \\
\hline HR122 & 3857 & 17 July & 20.8 & 0.39 & 9.9 & 16.2 & 69.5 & 47.8 \\
\hline 'Tulameen' & 3755 & 23 July & 24.8 & 0.31 & 12.0 & 17.4 & 46.4 & 35.9 \\
\hline HR158 & 3636 & 12 July & 19.8 & 0.43 & 7.8 & 15.5 & 108.5 & 29.2 \\
\hline ZN05005 & 3618 & 10 July & 19.2 & 0.34 & 9.4 & 18.1 & 120.7 & 57.4 \\
\hline NR10 & 3553 & 13 July & 20.1 & 0.30 & 9.6 & 17.3 & 74.6 & 52.0 \\
\hline ZNK033 & 3532 & 17 July & 23.3 & 0.37 & 11.9 & 15.1 & 74.6 & 41.2 \\
\hline ZNJ042 & 3509 & 13 July & 19.2 & 0.27 & 9.9 & 16.2 & 78.6 & 46.8 \\
\hline ZN05012 & 3497 & 17 July & 22.4 & 0.24 & 11.6 & 16.0 & 81.7 & 48.7 \\
\hline 'Meeker' & 3424 & 20 July & 24.0 & 0.30 & 11.4 & 14.8 & 52.9 & 44.6 \\
\hline 'Haida' & 3380 & 17 July & 20.3 & 0.28 & 9.4 & 14.7 & 77.1 & 41.5 \\
\hline 'Saanich' & 3371 & 19 July & 23.5 & 0.37 & 10.1 & 14.4 & 53.7 & 31.0 \\
\hline NR9 & 3261 & 19 July & 24.6 & 0.36 & 9.6 & 15.1 & 59.1 & 29.3 \\
\hline HR104 & 3212 & 19 July & 22.5 & 0.41 & 10.5 & 16.2 & 66.0 & 37.6 \\
\hline 'Wakefield' & 3192 & 21 July & 21.5 & 0.44 & 11.7 & 22.1 & 107.3 & 70.7 \\
\hline 'Cuthbert' & 3186 & 22 July & 22.7 & 0.24 & 12.4 & 12.5 & 67.1 & 42.0 \\
\hline 'Coho’' & 3182 & 23 July & 21.4 & 0.46 & 11.7 & 17.9 & 60.2 & 29.0 \\
\hline 'Moutere' & 3174 & 17 July & 21.0 & 0.25 & 9.6 & 15.4 & 82.1 & 41.1 \\
\hline 'Encore' & 3157 & 23 July & 20.6 & 0.27 & 9.4 & 16.7 & 29.9 & 47.2 \\
\hline NR12 & 3046 & 19 July & 22.7 & 0.26 & 10.4 & 14.0 & 49.6 & 44.7 \\
\hline ZN05015 & 2795 & 19 July & 23.9 & 0.27 & 9.5 & 17.4 & 45.9 & 48.0 \\
\hline 'Taylor' & 2675 & 22 July & 23.1 & 0.29 & 9.0 & 17.6 & 56.0 & 47.9 \\
\hline ZN05018 & 2546 & 19 July & 24.1 & 0.36 & 9.2 & 17.1 & 83.4 & 41.7 \\
\hline 'Killarney' & 2488 & 20 July & 22.3 & 0.17 & 9.9 & 17.7 & 64.3 & 27.9 \\
\hline 'Vene' & 2384 & 17 July & 22.1 & 0.22 & 11.4 & 15.0 & 49.5 & 46.8 \\
\hline 'Prelude' & 2309 & 12 July & 18.8 & 0.22 & 9.0 & 18.8 & 58.3 & 22.9 \\
\hline 'Boyne' & 2305 & 18 July & 20.9 & 0.20 & 8.6 & 17.5 & 86.1 & 34.2 \\
\hline 'Latham' & 2137 & 21 July & 22.2 & 0.24 & 8.9 & 18.7 & 91.3 & 35.3 \\
\hline 'Nova' & 2048 & 16 July & 19.4 & 0.30 & 7.8 & 19.0 & 111.5 & 25.7 \\
\hline 'K81-6' & 1944 & 19 July & 21.7 & 0.21 & 9.0 & 19.5 & 51.7 & 28.6 \\
\hline Mean & 3157 & 19 July & 22.4 & 0.32 & 9.9 & 16.8 & 68.5 & 41.2 \\
\hline Mean SE & 480.7 & 2.28 & 1.45 & 0.025 & 0.31 & 0.81 & 6.68 & 4.46 \\
\hline Minimum SE & 365.3 & 1.82 & 1.14 & 0.022 & 0.28 & 0.69 & 5.90 & 3.93 \\
\hline Maximum SE & 569.4 & 2.87 & 1.73 & 0.035 & 0.44 & 1.10 & 9.17 & 5.81 \\
\hline LSD $(0.05)$ & 961.4 & 4.6 & 2.89 & 0.05 & 0.62 & 1.62 & 13.36 & 8.92 \\
\hline
\end{tabular}

$\overline{{ }^{\mathrm{z}} \text { Maximum values are indicated in bold and minima in italic. Least significant difference [LSD (5\% significance level)], mean, minimum, and }}$ maximum SE estimates also are shown.

${ }^{\mathrm{y}}$ TYLD = total yield; MHD = midharvest day; HSP = harvest span; FIRM = firmness; SS = soluble solids; ACID = acidity; TACY = total anthocyanins; TELG = total ellagitannins. 
Table 2. Narrow-sense heritability estimates $\left(h^{2}\right)$, and their SE, for each trait in each year (and mean $h^{2}$ of all years) from red raspberry pairwise study.

\begin{tabular}{|c|c|c|c|c|c|c|c|}
\hline \multirow[b]{2}{*}{ Trait $^{z}$} & \multicolumn{2}{|c|}{2009} & \multicolumn{2}{|c|}{2010} & \multicolumn{2}{|c|}{2011} & \multirow[b]{2}{*}{ Mean $h^{2}$} \\
\hline & $h^{2}$ & SE & $h^{2}$ & $\mathrm{Se}$ & $h^{2}$ & SE & \\
\hline TYLD & 0.20 & 0.168 & 0.18 & 0.102 & 0.29 & 0.149 & 0.22 \\
\hline MHD & - & - & 0.57 & 0.250 & 0.62 & 0.265 & 0.59 \\
\hline HSP & - & - & 0.36 & 0.164 & 0.48 & 0.211 & 0.42 \\
\hline FIRM & 0.49 & 0.172 & 0.58 & 0.185 & 0.55 & 0.180 & 0.54 \\
\hline SS & 0.58 & 0.211 & 0.79 & 0.280 & 0.81 & 0.284 & 0.73 \\
\hline ACID & 0.54 & 0.192 & 0.44 & 0.152 & 0.38 & 0.131 & 0.45 \\
\hline TACY & 0.71 & 0.251 & 0.64 & 0.210 & 0.65 & 0.224 & 0.67 \\
\hline TELG & 0.32 & 0.121 & 0.57 & 0.198 & 0.48 & 0.159 & 0.46 \\
\hline
\end{tabular}

${ }^{\mathrm{z}}$ TYLD $=$ total yield; MHD = midharvest day; HSP = harvest span; FIRM = firmness; $\mathrm{SS}=$ soluble solids; ACID = acidity; TACY $=$ total anthocyanins; TELG = total ellagitannins.

Table 3. Genetic (bottom triangle) and phenotypic (upper triangle) correlations, averaged over the 3 years, for all pairs of traits from THE red raspberry pairwise study. ${ }^{\mathrm{z}}$

\begin{tabular}{lrrrrrrrr}
\hline Trait $^{y}$ & TYLD & MHD & HSP & FIRM & SS & ACID & TACY & TELG \\
\hline TYLD & & 0.12 & 0.24 & 0.06 & 0.14 & -0.07 & -0.12 & 0.08 \\
MHD & 0.35 & & 0.54 & 0.27 & 0.22 & 0.12 & -0.31 & 0.07 \\
HSP & 0.35 & 0.80 & & 0.19 & 0.03 & 0.09 & -0.23 & 0.02 \\
FIRM & $\mathbf{0 . 5 1}$ & 0.33 & 0.34 & & -0.04 & 0.27 & 0.16 & 0.01 \\
SS & 0.27 & 0.35 & -0.07 & -0.16 & & -0.06 & -0.13 & 0.18 \\
ACID & -0.35 & 0.15 & 0.22 & 0.39 & -0.24 & & 0.25 & 0.03 \\
TACY & -0.28 & -0.57 & -0.43 & 0.22 & -0.31 & 0.32 & & 0.15 \\
TELG & 0.18 & 0.27 & 0.01 & 0.02 & 0.27 & 0.22 & 0.11 &
\end{tabular}

${ }^{\bar{z}}$ Correlations with total yield (TYLD) which are $>0.5$ are marked in bold, and pairs for which the magnitude of the difference between the genetic and phenotypic correlations is large (arbitrarily defined as > 0.4 ) are shown with a gray background.

yTYLD = total yield; MHD = midharvest day; HSP = harvest span; FIRM $=$ firmness; $\mathrm{SS}=$ soluble solids; $\mathrm{ACID}=$ acidity; $\mathrm{TACY}=$ total anthocyanins; TELG $=$ total ellagitannins.

Table 4. Genotype $\times$ year correlations $\left(\mathrm{r}_{\mathrm{GY}}\right)$, and their SE, for each trait between all year pairs from red raspberry pairwise study.

\begin{tabular}{|c|c|c|c|c|c|c|}
\hline \multirow[b]{2}{*}{ Trait $^{z}$} & \multicolumn{2}{|c|}{ 2009:2010 } & \multicolumn{2}{|c|}{$2010: 2011$} & \multicolumn{2}{|c|}{ 2009:2011 } \\
\hline & $\mathrm{r}_{\mathrm{GY}}$ & SE & $\mathrm{r}_{\mathrm{GY}}$ & SE & $r_{\mathrm{GY}}$ & SE \\
\hline TYLD & - & - & 0.56 & 0.450 & - & - \\
\hline MHD & - & - & 0.83 & 0.076 & - & - \\
\hline HSP & 0.66 & 0.247 & 0.89 & 0.054 & 0.26 & 0.267 \\
\hline FIRM & 0.94 & 0.017 & 0.95 & 0.019 & 0.92 & 0.020 \\
\hline SS & 0.88 & 0.044 & 0.97 & 0.010 & 0.91 & 0.019 \\
\hline ACID & 0.96 & 0.016 & 0.98 & 0.011 & 0.94 & 0.020 \\
\hline TACY & 0.94 & 0.054 & 0.98 & 0.146 & 0.95 & 0.050 \\
\hline TELG & 0.80 & 0.048 & 0.88 & 0.029 & 0.67 & 0.069 \\
\hline
\end{tabular}

${ }^{2}$ TYLD $=$ total yield; MHD = midharvest day; HSP = harvest span; FIRM = firmness; $\mathrm{SS}=$ soluble solids; $\mathrm{ACID}=$ acidity; $\mathrm{TACY}=$ total anthocyanins; TELG $=$ total ellagitannins.

\section{Discussion}

For all traits measured, we found large variation in parental breeding values, which is consistent with previous reports of genetic variation in the genus Rubus (Connor et al., 2005; Dossett and Finn, 2007; Luby and McNicol, 1994). Therefore, our study confirms that good genetic progress should be able to be made in the development of new raspberry cultivars suitable for the machine-harvest processing market. This is despite parental material in our study being highly related and representing only a small proportion of the genetic diversity of $R$. idaeus.

This is the first report of inheritance and genetic correlations of fruit SS, FIRM, ACID, and TELG in red raspberries. We have shown that these traits all have high to moderate heritability estimates, indicating that reasonable progress should be able to be made in improving these traits through breeding based on single plant genotypes. Our heritability estimates for TACY, TYLD, HSP, and MHD are consistent with those of Stephens et al. (2009), who measured heritability for TACY $\left(h^{2}=0.61\right)$, TYLD $\left(h^{2}=0.24\right)$, HSP $\left(h^{2}=0.77\right)$, and MHD $\left(h^{2}=0.56\right)$ on a factorial study in New Zealand over one season. The fact that estimates of heritability could not be extracted from the model for MHD and HSP in 2009 is likely to be because of the young age of the plants and lack of consistent quantities of fruit picked during the season. Also, only one plant in each plot was harvested in 2009 vs. two harvested in 2010 and 2011.

We found a moderate to low negative genetic correlation between TACY and TYLD $\left(r_{G}=-0.28\right)$, whereas Stephens et al. (2009) found the correlation to be negative and moderately high $\left(r_{G}=-0.64\right)$, which suggests genetic improvement for TACY and TYLD concurrently may be more difficult to achieve. Stephens et al. (2009) suggest that the reason for this might be because plants that use photosynthate for increased polyphenol production might have less photosynthate for vegetative growth and fruit production. By demonstrating two scenarios using different economic weightings (Fig. 1), we have shown that the use of selection index is useful when breeders are faced with selection of multiple traits including those negatively correlated with TYLD. We also found a negative genetic correlation between fruit ACID and TYLD $\left(r_{G}=-0.35\right)$, meaning selection for high-yielding genotypes could result in lower fruit acidity. Along with volatile compounds, sugar and acids are important components of flavor in raspberry (Hall et al., 2009). Additionally, for processing raspberry, fruit with evaluated levels of sugar and acids are desirable because this results in higher yield of concentrated juice product and fruit with higher acidity is desirable for jam-making because it helps jam set, aids preservation, and stabilizes fruit color (Daubeny, 1996). We found little in the literature on genetic correlations between fruit quality traits (SS, FIRM, ACID, TACY) and TYLD in small fruit. In strawberry (Fragaria $\times$ ananassa), Monma and Takada (1991) found negative correlations between TYLD and both SS and ACID. In tomato (Solanum lycopersicum), Bernousi et al. (2011) found weak positive correlations between TYLD and ACID and SS, and Ramana et al. (2007) found ACID and SS were not significantly correlated with TYLD. Our results are similar to those of Rakonjac (2006), who found a positive genetic correlation between TYLD and SS and a negative correlation between TYLD and ACID content in peach (Prunus persica).

In our study, weak positive genetic correlations between SS and TELG and TYLD mean that selecting for high-yielders should not result in an overall reduction in concentrations of these compounds.

Positive genetic correlations were found between TYLD and MHD and HSP and this could be because higher yielding 


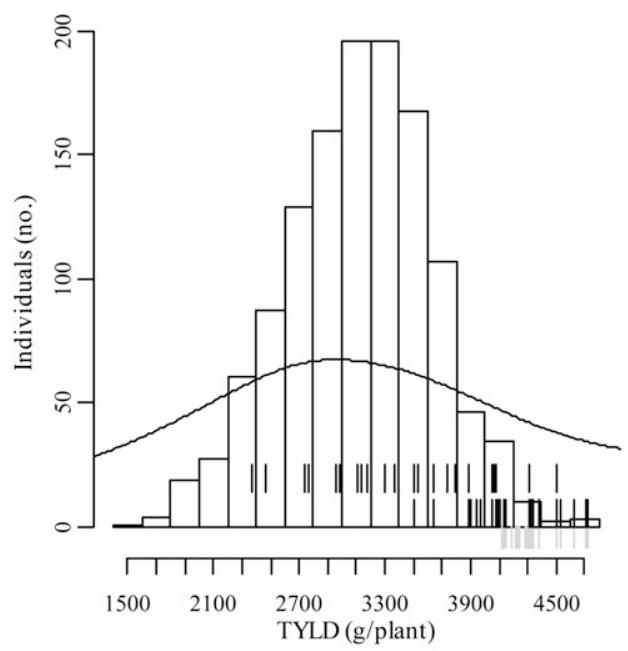

$\mathrm{B}$

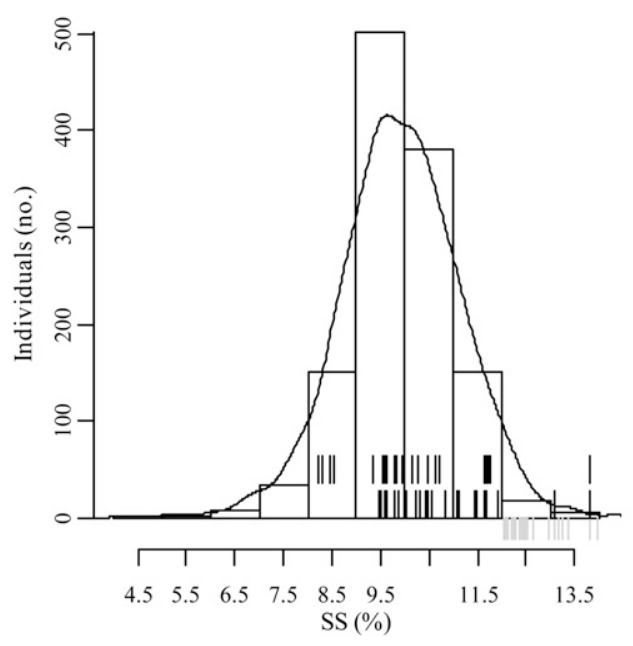

C



D

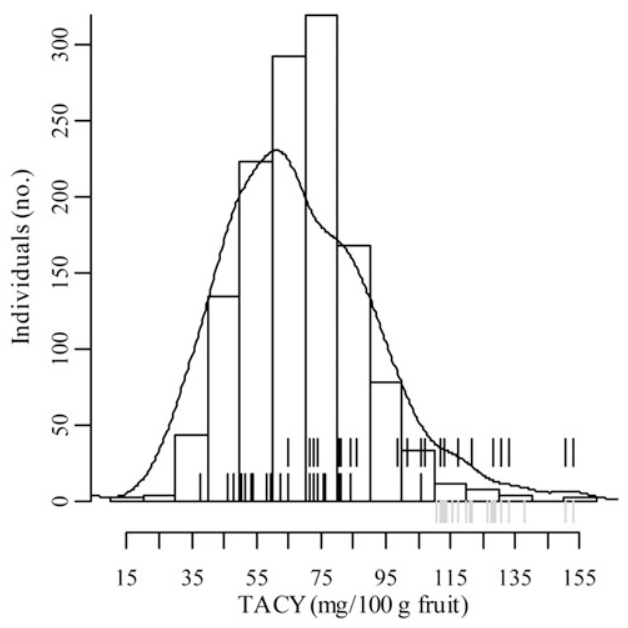

Fig. 1. Frequency histograms of breeding values from multivariate analysis from red raspberry pairwise study: (A) total yield (TYLD), (B) soluble solids (SS), (C) fruit firmness (FIRM), and (D) total anthocyanins (TACY). Bars represent the empirical breeding values (eBVs) and Kernel density line represents the raw data. Gray (lower) tick marks represent the top 25 genotypes based on eBV for each trait and black (upper) tick marks represent the top 25 genotypes based on the selection index. Lower black tick marks based on economic weights: 0.2, 80, 1500, and 0.8 for total yield, soluble solids, fruit firmness, and total anthocyanins, respectively, and upper black tick marks based on economic weights $0.2,80,1500$, and 10 , respectively.

plants need more time to develop longer fruiting laterals with higher numbers of fruit. Likewise, a strong positive genetic correlation was found between MHD and HSP, probably because later fruiting laterals take more time to develop and hence the ripening season is longer. This has implications for the harvest timing of new cultivars, because highest yielding cultivars are likely to be later ripening and have a longer harvest season and it maybe more difficult to achieve high-yielding earlyripening cultivars.

We found a strong positive genetic correlation between FIRM and TYLD (and low phenotypic correlation) and this was not expected. We found no reports in the literature of correlations between FIRM and TYLD in red raspberry or other small fruit. Although the positive correlation is encouraging from a breeding point of view, we can offer little explanation for this observation except that it could be because we included a number of high-yielding and firm-fruited breeding lines in our study. This is likely to be a result of past selection pressure for high yield and firm fruit and thus narrowing of the gene pool.

Fruit quality traits FIRM, SS, ACID, TACY, and TELG all had low $\mathrm{G} \times \mathrm{Y}$ interaction; therefore, measurements made in the first fruiting year were comparable to those of later years. This is in contrast to TYLD, MHD, and HSP and some yield components (Stephens et al., 2012) in which significant $G \times Y$ interactions occur. Our results suggest that for these production traits at least, selection decisions should be made in the second and third fruiting seasons, whereas selection decisions based on fruit quality traits could be made in the first fruiting season. We could not obtain meaningful $\mathrm{G} \times \mathrm{Y}$ correlations for TYLD and MHD when 2009 data were included and this may be because we only harvested one plant per plot in 2009 and/or because the plants were still establishing. However, we would suggest these correlations would be significantly lower than that obtained for 2010$2011\left(r_{g y}=0.56\right)$. Therefore, TYLD (and HSP, MHD) measurements should be made on second- and third-year harvests.

Most raspberry breeding programs demand many traits to be present in a single genotype and the use of recurrent selection procedures through the selection index approach could offer breeders a robust technique to help to achieve this goal. One of the selection index scenarios we present had a strong bias toward high yield and firm fruit. However, our graphical representation allows a breeder to gauge the impact of adjusting the weight to put more emphasis on other traits. Traits negatively correlated with TYLD such as TACY and ACID present a challenge to breeders, although we have shown index selection will still enable genetic gain, albeit at a slower rate.

To produce successful cultivars, raspberry breeders require target traits to be heritable, positively correlated and in populations with sufficient genetic variation to allow improvement. Our study found moderate to high heritability estimates for red raspberry fruit quality traits and positive genetic correlations between TYLD, MHD, and HSP and fruit quality parameters FIRM, SS and TELG, which indicates genetic gain for TYLD and these fruit quality traits should be achievable. In our study, $\mathrm{G} \times \mathrm{Y}$ interaction was low for fruit quality traits, suggesting measurements made in the first fruiting season are indicative of subsequent seasons, whereas TYLD, MHD, and HSP had higher $\mathrm{G} \times \mathrm{Y}$ interaction and thus should be measured in the second and/ or third seasons. To achieve all desirable traits in one genotype, multitrait selection through selection index offers promise and 
we have demonstrated how this approach could work when breeding for high yield and fruit quality in red raspberry, including traits negatively correlated with TYLD. From our studies, an efficient strategy for raspberry breeding might be to measure fruit chemistry components, berry weight, and lateral length in the first season (Stephens et al., 2012) followed by yield measurements in the second and/or third seasons on selected progeny and applying the selection index.

\section{Literature Cited}

Bakkalbasi, E., O. Mentes, and N. Artik. 2009. Food ellagitanninsOccurrence, effects of processing and storage. Crit. Rev. Food Sci. Nutr. 49:283-298.

Barritt, B.H. 1982. Heritability and parent selection for fruit firmness in red raspberry. HortScience 17:648-649.

Barritt, B.H. and L.C. Torre. 1975. Fruit anthocyanin pigments of red raspberry cultivars. J. Amer. Soc. Hort. Sci. 100:98-100.

Beatson, R.A., P.A. Alspach, A.J. Currie, P.M. Harris-Virgin, and A. White. 2011. Genetic parameters for fruit traits of interspecific Actinidia hybrids. Acta Hort. 913:89-96.

Bernousi, I., A. Emami, M. Tajbakhsh, R. Darvishzadeh, and M. Henareh. 2011. Studies on genetic variability and correlation among the different traits in Solanum lycopersicum L. Notulae Botanicae Horti Agrobotanici Cluj-Napoca 39:152-158.

Bushman, B.S., B. Phillips, T. Isbell, B. Ou, J.M. Crane, and S.J. Knapp. 2004. Chemical composition of caneberry (Rubus spp.) seeds and oils and their antioxidant potential. J. Agr. Food Chem. 52:7982-7987.

Butler, D.G., B.R. Cullis, A.R. Gilmour, and B.J. Gogel. 2006. ASReml-R reference manual, release 2. Queensland Department of Primary Industries and Fisheries, Brisbane, Australia.

Cerda, B., F.A. Tomas-Barberan, and J.C Espin. 2005. Metabolism of antioxidant and chemopreventative ellagtannins from strawberries, raspberries, walnuts, and oak-aged wine in humans: Identification of biomarkers and individual variability. J. Agr. Food Chem. 53:227-235.

Connor, A.M., T.K. McGhie, M.J. Stephens, H.K. Hall, and P.A. Alspach. 2005. Variation and heritability estimates of anthocyanins and their relationship to antioxidant activity in a red raspberry factorial mating design. J. Amer. Soc. Hort. Sci. 130:534-542.

Daubeny, H.A. 1996. Brambles, p. 109-190. In: Janick, J. and J. N. Moore (eds.). Fruit breeding. Wiley, New York, NY.

de Oliveira, E.J., V.D. Santos, D.S. de Lima, D. Machado, R.S. Lucena, T.B.N. Motta, and M.D. Castellen. 2008. Selection on yellow passion fruit progenies by multivariate indices. Pesquisa Agropecu. Bras. 43:1543-1549.

Dieters, M.J., T.L. White, R.C. Littell, and G.R. Hedge. 1995. Application of approximate variances of variance-components and their ratios in genetic tests. Theor. Appl. Genet. 91:15-24.

Dossett, M. and C. Finn. 2007. Variation and inheritance of vegetative and reproductive traits in black raspberry (Rubus occidentalis L.). HortScience 42:897-898.

Dossett, M., J. Lee, and C.E. Finn. 2008. Inheritance of phenological, vegetative, and fruit chemistry traits in black raspberry. J. Amer. Soc. Hort. Sci. 133:408-417.

Falconer, D.S. and T.F.C. Mackay. 1996. Introduction to quantitative genetics. Longmans Green, Harlow, UK.

Gilmour, A.R., B.R. Cullis, and A.P. Verbyla. 1997. Accounting for natural and extraneous variation in the analysis of field experiments. J. Agr. Biol. Environ. Stat. 2:269-293.
Hall, H.K., K.E. Hummer, A.R. Jamieson, S.N. Jennings, and C.A. Weber. 2009. Raspberry breeding and genetics. Plant Breed. Rev. 32:39-382.

Hazel, L.N. 1943. The genetic basis for constructing selection indexes. Genetics 28:28-476.

Hazel, L.N., G.E. Dickerson, and A.E. Freeman. 1994. The selection index - Then, now, and for the future. J. Dairy Sci. 77:3236-3251.

Henderson, C.R. 1977. Best linear unbiased estimation and prediction under a selection model. Biometrics 31:423-477.

Khanizadeh, S., D. Rekika, B. Ehsani-Moghaddam, R. Tsao, R. Yang, M.T. Charles, J.A. Sullivan, L. Gauthier, A. Gosselin, A.M. Potel, G. Reynaud, and E. Thomas. 2009. Horticultural characteristics and chemical composition of advanced raspberry lines from Quebec and Ontario. Food Sci. Technol. 42:893-898.

Knight, V.H., D.L. Jennings, and R.J. McNicol. 1989. Progress in the UK raspberry breeding programme. Acta Hort. 262:93-103.

Luby, J.J. and R.J. McNicol. 1994. The potential for exploitation of genetic resources in Fragaria, Rubus and Ribes. Asp. Appl. Biol. 39:7-14.

Lynch, M. and B. Walsh. 1998. Estimation of breeding values, p. 745778. In: Lynch, M. and B. Walsh (eds.). Genetics and analysis of quantitative traits. Sinauer Assoc., Sunderland, MA.

Monma, S. and K. Takada. 1991. Inheritance of soluble solids content and acidity in strawberry (Fragaria $\times$ Ananassa Duch). J. Jpn. Soc. Hort. Sci. 59:719-726.

Olsson, M.E., K.-E. Gustavsson, S. Andersson, A. Nillson, and R.-D. Duan. 2004. Inhibition of cancer cell proliferation in vitro by fruit and berry extracts and correlations with antioxidant levels. J. Agr. Food Chem. 42:7264-7271.

Patterson, H.D. and E.R. Williams. 1976. A new class of resolvable incomplete block designs. Biometrika 63:83-92.

Piepho, H.P. and E.R. Williams. 2006. A comparison of experimental designs for selection in breeding trials with nested treatment structure. Theor. Appl. Genet. 113:1505-1513.

R Core Development Team. 2010. R: A language and environment for statistical computing. R Foundation for Statistical Computing, Vienna, Austria.

Rakonjac, V. 2006. Geneticka analiza prinosa i kvaliteta ploda sorti i hibrida breskve. Vocarstvo 40:289-299.

Ramana, C.V., V.G. Shankar, S.S. Kumar, and P.V. Rao. 2007. Trait interrelationship studies in tomato (Lycopersicon esculentum Mill.). Res. Crops 8:213-218.

Ross, H.A., G.J. McDougall, and D. Stewart. 2007. Antiproliferative activity is predominantly associated with ellagitannins in raspberry extracts. Phytochemistry 68:218-228.

Seeram, N.P., W.J. Aronson, Y. Zhang, S.M. Henning, A. Moro, R.P. Lee, N. Sartippour, D.M. Harris, M. Rettig, M.A. Suchard, A.J. Pantuck, A. Belldegrun, and D. Heber. 2007. Pomegranate ellagitannin-derived metabolites inhibit prostate cancer growth and localize to the mouse prostate gland. J. Agr. Food Chem. 55:7732-7737.

Stephens, M.J., P. Alspach, R.A. Beatson, C. Winefield, and E. Buck. 2012. Genetic parameters and breeding for yield in red raspberry. J. Amer. Soc. Hort. Sci. 137:229-235.

Stephens, M.J., J. Scalzo, P.A. Alspach, R.A. Beatson, and A.M. Connor. 2009. Genetic variation and covariation of yield and phytochemical traits in a red raspberry factorial study. J. Amer. Soc. Hort. Sci. 134:445-452.

Viljanen, K., P. Kylly, R. Kivikari, and M. Heinonen. 2004. Inhibition of protein and lipid oxidation in liposomes by berry phenolics. J. Agr. Food Chem. 52:7419-7424. 